\title{
Biosurfactants Production from Low Cost Substrate and Degradation of Diesel Oil by a Rhodococcus Strain
}

\author{
Z. Sadouk ${ }^{1,2 *}$, H. Hacene ${ }^{2}$ and A. Tazerouti ${ }^{1}$ \\ 1 Laboratoire de Synthèse Organique, Faculté de Chimie, Université des Sciences et de la Technologie H. Boumediène (USTHB), \\ BP 32, El-Alia, Bab-Ezzovar, 16111 Algiers - Algeria \\ 2 Laboratoire de Microbiologie, Faculté des Sciences Biologiques, Université des Sciences et de la Technologie H. Boumediène (USTHB), \\ BP 32, El-Alia, Bab-Ezzovar, 16111 Algiers - Algeria \\ e-mail: z.sadouk@hotmail.com - h_hacene@yahoo.fr - ameltazerouti@gmail.com \\ * Corresponding author
}

\begin{abstract}
Résumé - Production de biosurfactants sur un substrat économique et dégradation du gasoil par une souche du genre Rhodococcus - L'aptitude d'une souche bactérienne du genre Rhodococcus à produire des agents tensioactifs à partir d'une huile de friture résiduelle de tournesol (RSFO) a été testée en milieu non renouvelé. Durant la culture avec RSFO comme seule source de carbone, à la concentration de $3 \%$ ( $\mathrm{vol} / \mathrm{vol})$, la souche bactérienne a synthétisé des substances de nature extracellulaire qui induisent une émulsification du milieu de culture avec un indice d'émulsion $\mathrm{E}_{24}$ de $63 \%$. Sous leur forme non purifiée, les substances extraites du milieu de culture abaissent la tension superficielle de l'eau jusqu'à $31,9 \mathrm{mN} \mathrm{m}^{-1}$. La croissance exponentielle de la bactérie utilisant RSFO comme seule source de carbone s'est développée au taux spécifique de $\mu=0,55 \mathrm{~d}^{-1}(\mathrm{~d}=$ jour). La concentration micellaire critique de l'extrait brut a atteint la valeur de $287 \mathrm{mg} \mathrm{L}^{-1}\left(\gamma \mathrm{CMC}=31,9 \mathrm{mN} \mathrm{m}^{-1}\right)$. Après methylesterification, la fraction lipidique du biosurfactant a été analysée par GC-MS / EI, qui révèle la présence d'esters méthyliques d'acide gras. Le micro-organisme a été également cultivé avec le gasoil comme seule source de carbone à la concentration de $1 \%$ (vol/vol): la phase de croissance exponentielle s'est développée au taux de $\mu=0,02 \mathrm{~d}^{-1}$, sans production de substances émulsifiantes : le microorganisme semble développer différents modes d'assimilation de substrat, selon la nature de la source de carbone. Les agents tensioactifs synthétisés à partir de l'huile de tournesol résiduelle de friture par Rhodococcus erythropolis 16 LM.USTHB pourraient être utilisés, de manière rentable, dans l'industrie pétrolière avec des spécifications minimales de pureté pour la restauration des sites contaminés par les hydrocarbures et dans la récupération du pétrole brut.
\end{abstract}

\footnotetext{
Abstract - Biosurfactants Production from Low Cost Substrate and Degradation of Diesel Oil by a Rhodococcus Strain - The ability of a Rhodococcus strain to produce surface-active agents from residual sunflower frying oil (RSFO) has been screened in batch cultures. During cultivation with RSFO at the concentration 3\% (vol/vol), the strain has synthesized extra-cellular compounds which increase the $E_{24}$ emulsion index of the culture medium up to 63\%. In their crude form, these substances lower the surface tension of water until $31.9 \mathrm{mN} \mathrm{m}^{-1}$. The exponential growth with RSFO as the sole carbon source has developed at a specific growth rate $\mu=0.55 d^{-1}$. The critical micelle concentration of the crude
} 
product reached the value $287 \mathrm{mg} \mathrm{L}^{-1}\left(\gamma C M C=31.9 \mathrm{mN} \mathrm{m}^{-1}\right)$. After methylesterification, the lipid fraction of biosurfactants has been analyzed by GC-MS in EI, which reveals the presence of fatty acid methyl esters. The microorganism was also cultivated with the diesel oil as the sole carbon source at the concentration $1 \%(\mathrm{vol} / \mathrm{vol})$ : the active growth phase has developed at rate $\mu=0.02 \mathrm{~d}^{-1}$, without production of emulsifying substance: the microorganism seems to develop different modes of substrate uptake, according to the nature of the carbon source. The potential use of surface-active agents synthesized on RSFO by Rhodococcus erythropolis 16 LM.USTHB is in the oil industry with minimum purity specification, so that crude preparation could be used, at low cost, in clean-up of hydrocarbons contaminated sites and for enhanced oil recovery.

\section{ABBREVIATIONS}

RSFO Residual sunflower frying oil

MSM Mineral salts medium

CMC Critical micelle concentration

$\mu \quad$ Specific growth rate

$\gamma_{\mathrm{CMC}}$ Surface tension with whose CMC is reached

\section{INTRODUCTION}

Surfactants are amphiphilic compounds, which can reduce surface and interfacial tensions by accumulating at the interface of immiscible fluids. Surfactants of biological origin are becoming important biotechnology products for industrial applications, due to their specific modes of action and widespread applicability [1,2]. Biosurfactants have been tested in environmental applications such as enhanced oil recovery, bioremediation and dispersion of oil spills [2,3]. They have been used to increase the uptake of organic compounds with limited water solubility during bacterial growth. They can affect the rate of hydrocarbons biodegradation in two ways [4-6]: by increasing solubilization and dispersion of the hydrocarbons and by changing the affinity between microbial cells and hydrocarbons by inducing increases in cell surface hydrophobicity. Biodegradability and low environmental impact are some of the advantages shown by these compounds compared with surfactants chemically synthesized. However, the production costs of the separation and the concentration of biosurfactants are the limiting factor which prevents their large-scale production [7]. Thereby, the potential use of biosurfactants is in the oil industry with minimum purity specification [8], so that crude preparation could be used in clean-up of hydrocarbons contaminated sites and for Enhancing Oil Recovery (EOR). Biosurfactants aid EOR by lowering interfacial tension at the oil-rock interface; this reduces capillarity forces that prevent oil from moving through rock pores [9]. It is reported in the literature that the genus Pseudomonas and Serratia grown on vegetable oils are mainly used in the field of the biosurfactants production
$[10,11]$; but to our knowledge, there is no data on the use of Rhodococcus erythropolis strains for producing biosurfactants with residual sunflower frying oil. In the present study, we investigate the ability of a Rhodococcus erythropolis strain to produce biosurfactants from used vegetable oil in order to reduce the wastes generated by food industries. For this purpose, surface tension, critical micelle concentration (CMC) and $\mathrm{E}_{24}$ emulsion index have been investigated to show surface activity of crude biosurfactant produced. The lipid fraction has been analyzed by GC-MS in EI.

\section{MATERIALS AND METHODS}

\subsection{Microorganism, Media and Culture Conditions}

Rhodococcus erythropolis 16 LM. USTHB is a strain isolated from water polluted by rejections of 2-Mercaptobenzothiazole and its derivatives used in the rubber industry. The strain was a kind gift of the industrial microbiology and biochemistry laboratory of the Leuwen catholic university to Pr. A. Chikhi. The mineral salts medium (MSM) used for all incubations contained $\left(\mathrm{g} \mathrm{L}^{-1}\right): \mathrm{KH}_{2} \mathrm{PO}_{4}: 10 ; \mathrm{K}_{2} \mathrm{HPO}_{4}$ : 3; $\mathrm{NH}_{4} \mathrm{NO}_{3}: 2$; (solution A) and $\mathrm{MgSO}_{4}\left(7 \mathrm{H}_{2} \mathrm{O}\right): 0.3 ; \mathrm{NaCl}: 0.1$; $\mathrm{CaCl}_{2}: 0.01 ; \mathrm{MnCl}_{2}: 0.001 ; \mathrm{CuCl}_{2}: 0.001 ; \mathrm{FeSO}_{4}: 0.001$; $\mathrm{ZnSO}_{4}: 0.001$ and $\mathrm{MoO}_{3}: 0.0001$. The $\mathrm{pH}$ of the solution A was adjusted to 6.25 with $\mathrm{NaOH}$ before autoclaving $\left(120^{\circ} \mathrm{C}\right.$, $20 \mathrm{~min}$ ). For the other salts, mother solutions have been prepared and autoclaved separately; then, an appropriate volume of each solution was added aseptically at solution A to form the MSM. The diesel oil was purchased from a service station SONATRACH (Algerian Petroleum Company) and used as the carbon source. The sunflower oil comes from the refinery Cevital (Algeria); it was used to fry potato chips, then recovered and filtered at the end of the cooking: the filtrate was used as carbon source. A preculture was carried out in two $250 \mathrm{~mL}$-Erlenmeyer flasks containing $50 \mathrm{~mL}$ of MSM supplemented either with RSFO at the concentration $1 \%$ ( $\mathrm{vol} / \mathrm{vol}$ ) or with diesel oil at the concentration $0.25 \%$ 
( vol $/ \mathrm{vol})$. The flasks were incubated during 48 hours at $27^{\circ} \mathrm{C}$ under 90 mpm horizontal shaking ( GERHARDT).

$8 \mathrm{~mL}$ of the preculture were inoculated into $500 \mathrm{~mL}$ Erlenmeyer flasks containing $100 \mathrm{~mL}$ of MSM added either with the RSFO at the concentration $3 \%(\mathrm{vol} / \mathrm{vol})$ or with diesel oil at the concentration $1 \%(\mathrm{vol} / \mathrm{vol})$. The flasks were incubated at $27^{\circ} \mathrm{C}$ under $90 \mathrm{mpm}$ horizontal shaking. All experiments were performed in duplicate and were reproducible to $\pm 6 \%$.

The cellular growth was monitored by the measure of the $\mathrm{OD}_{600}$ of the culture medium; due to the poorly soluble nature of diesel oil in water, the measures were achieved [12] by covering the cuvette with parafilm, inverting the cuvette five times, and then immediately determining the $\mathrm{OD}_{600}$.

\subsection{Calibration of the Spectrophotometer}

$30 \mathrm{~mL}$ of the culture broth were subjected to the first centrifugation at $4000 \mathrm{rpm}$ during 20 minutes; the precipitate was washed with physiological water, centrifuged again at $4000 \mathrm{rpm}$ during 20 minutes, then filtered through a membrane filter (Millipore Corp.; pore size: $0.45 \mu \mathrm{m}$ ) and dried at $105^{\circ} \mathrm{C}$ during 24 hours: the difference between the weight (expressed in $\mathrm{mg}$ ) of the filter before and after drying is reported to the liter $\left(\mathrm{mg} \mathrm{L}^{-1}\right)$. The operation is carried out with each bacterial culture sample after having measured the optical density of it by means of the spectrophotometer UVvisible UNICAM.

\subsection{Surface Tension and Emulsification Measurement of Culture Medium}

The release of surface-active agents into the bacterial culture by the microorganism during its growth was monitored by measuring the surface tension of the culture medium. The measurements were made on samples of the culture medium by means of tensiometer CSC-DUNOUY 40902 using the ring technique. Emulsifier activity [13] was measured by adding $6 \mathrm{~mL}$ of kerosene to $4 \mathrm{~mL}$ of aqueous sample and vortexing at high speed for $2 \mathrm{~min}$. Measurement was made 24 hours later. The emulsion index $\mathrm{E}_{24}$, which is most suitable for emulsifying biosurfactants [8], is the height of the emulsion layer multiplied by 100 , divided by the total height. The results were the average of three determinations and the standard deviation was $<4 \%$.

\subsection{Test of Localization}

To determine if the surface-active substance produced by the microorganism was released into the medium or remained associated with the cells, $20 \mathrm{~mL}$ of the culture medium were sampled after 4 days of incubation (during the exponential growth phase) and after 13 days of incubation (at the late stationary phase); the samples were filtered (filter pores size: $0.45 \mu \mathrm{m}$, Millipore Corp.) in order to separate the cell-free broth from the cells. The $\mathrm{E}_{24}$ emulsion test was carried out with $4 \mathrm{~mL}$ of each filtrate and the surface tension was measured with $10 \mathrm{~mL}$ of the filtrate.

\subsection{Recovery of Crude Extract}

A crude biosurfactant was extracted from the cell-free culture supernatant of $R$. erythropolis 16 LM-USTHB grown on residual sunflower frying oil, using the technique described in [14]; briefly, at the end of the cultivation on RSFO, and after the hydrophobic layer located at the surface has been removed, the culture medium was centrifuged at $12000 \mathrm{~g}$ at $4^{\circ} \mathrm{C}$. The supernatant was extracted by means of the organic solvent system $\mathrm{CH}_{2} \mathrm{Cl}_{2} / \mathrm{CH}_{3} \mathrm{OH}(2: 1, \mathrm{v} / \mathrm{v})$; the extract was concentrated under reduced pressure: resulting crude extract.

\subsection{Analytical Methods}

The coefficient of correlation between two statistical sequences was calculated by means of the program with (stats) of the software Maple 8 (Waterloo Maple Inc.).

The bacterial active growth phase was identified visually as the exponential part of a plot of the bacterial density versus incubation time; the specific growth rate $\mu$ was calculated by means of the Exp2PModl mode of the software "Origin 5.0" (Microcal software Inc.) according to the equation $\mathrm{OD}_{600}(T)=a \mathrm{e}^{\mu T}$.

The analysis of fatty acids in the culture broth was carried out as described in [14]: after the fermentation is completed, the residual RSFO was removed using the conventional repeated decantation technique. Broth culture was acidified with conc. $\mathrm{HCl}$ to a $\mathrm{pH}$ ca 2.0 and extracted with $50 \mathrm{~mL}$ ethyl acetate. The extract was dried over anhydrous sodium sulfate and evaporated to dryness under reduced pressure. The residue was dissolved in $5 \mathrm{~mL} \mathrm{CH} \mathrm{Cl}_{2} / \mathrm{CH}_{3} \mathrm{OH} /$ conc. $\mathrm{HCl}$ (10:1:1 by vol.) and heated for 90 minutes at $100^{\circ} \mathrm{C}$. After cooling, the fatty acid methyl esters were recovered in $\mathrm{CH}_{2} \mathrm{Cl}_{2}$, dried under nitrogen and dissolved in $1 \mathrm{~mL}$ n-octane for analysis by GC and GC-MS. Gas chromatographic analyses were performed on a Clarus $500 \mathrm{GC}$ from PerkinElmer. The column used is Elite-5MS ( $30 \mathrm{~m} \times 0.3 \mathrm{~mm} ; i . d ., 0.25 \mu \mathrm{m}$ film). The operating temperatures of the injector and detector were $250^{\circ} \mathrm{C}$ and $200^{\circ} \mathrm{C}$ respectively. The oven temperature program was as follows: $100^{\circ} \mathrm{C}$ for $0.5 \mathrm{~min}$, increase to $290^{\circ} \mathrm{C}$ at the rate $8^{\circ} \mathrm{C} \mathrm{min}^{-1}$, with an isothermal period of $20 \mathrm{~min}$ at the end. The GC-MS analyses were performed on the same chromatograph connected to a quadrupole mass spectrometer (Helium was the carrier gas). The electron impact ion source was maintained at $200^{\circ} \mathrm{C}$. The electron energy was set at $70 \mathrm{eV}$. To quantify the residue of unutilized RSFO, the hydrophobic layer located at the surface has been 
removed by means of the repeated decantation technique, recovered by addition of methanol, and weighted after evaporation of the solvent. Total sugar content was quantified on the crude extract by the conventional colorimetric method [15], using glucose as a standard and expressed in glucose equivalent.

\section{RESULTS AND DISCUSSION}

\subsection{Calibration of the Spectrophotometer}

The equation of the correlation curve relating $\mathrm{OD}_{600}$ to dry weight (Fig. 1) obtained during the bacterial exponential growth is:

$$
\text { Mass dries }\left(m g L^{-1}\right)=0,46 O D+44 ;(R=0,99)
$$

\subsection{Diesel Oil Degradation by Rhodococcus erythropolis 16 LM.USTHB}

At first, we evaluated the degradation capabilities of the diesel oil by the microorganism by cultivating it on MSM supplemented with diesel oil as the sole carbon source at the concentration $1 \%(\mathrm{vol} / \mathrm{vol})$. The evolution of the growth indicators is visualized in Figure 2. The exponential growth phase, which is the direct result of substrate uptake [16], is developed during 14 days at the rate $0.02 \mathrm{~d}^{-1}$, followed by a stationary phase which lasted 3 days; the rate of the kerosene-water emulsion index $\mathrm{E}_{24}$ did not show any variation $\left(\mathrm{E}_{24}=0 \%\right)$ during the bacterial culture, which means that the active growth phase is developed without production of emulsifying substance. It appears that $R$. erythropolis 16 LM.USTHB assimilated the diesel oil according to the mode of direct accession per contact between the diesel oil droplets and the bacterial cell. Such hydrocarbons uptake mechanism has been extensively reported [17-20]. It should be noted that diesel oil is a complex hydrocarbons mixtures that are highly variable in structure and in susceptibility to biodegradation; in addition, fresh diesel oil contains a light hydrocarbon fraction, rich in aromatic compounds that may be toxic to some strains. Nevertheless, the same experiment with weathered diesel oil could have shown much higher degradation and surfactant production levels, as it has been described in a previous work [21] with a rhamnolipid-producing strain of Pseudomonas aeruginosa.

\subsection{Degradation of the Residual Sunflower Frying Oil}

Afterwards, we evaluated the capabilities of the microorganism to degrade RSFO used as the sole carbon source at the concentration $3 \%$ ( $\mathrm{vol} / \mathrm{vol}$ ), which corresponds to $27 \mathrm{~g} \mathrm{~L}^{-1}$. The growth of the microorganism on the culture medium evaluated by the measure of optical density $\left(\mathrm{OD}_{600}\right.$ at the dilution $10^{-1}$ ) as well as the time course of the $\mathrm{pH}$ of the bacterial culture is shown in Figure 3.

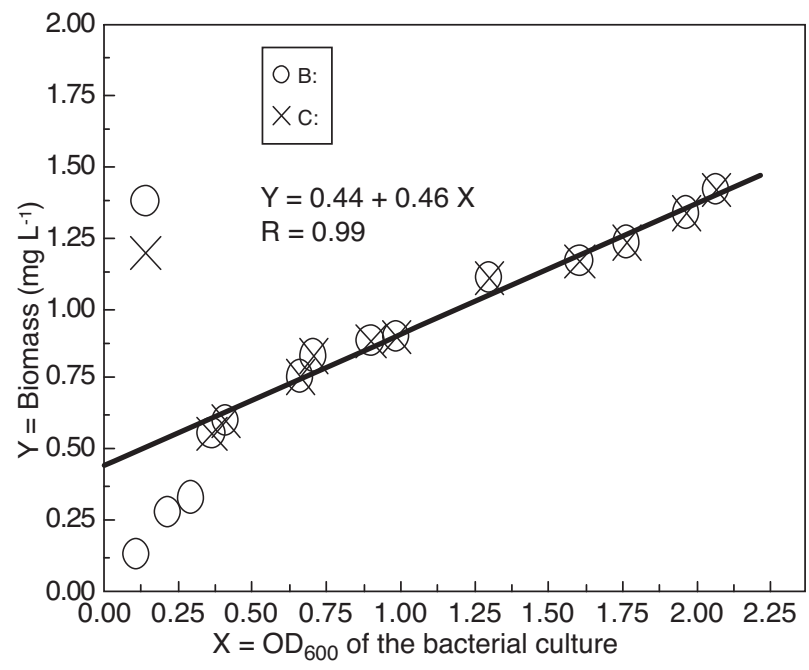

Figure 1

Calibration of the spectrophotometer for a reading in mass dries; (0) Distribution of the mass dries vs. $\mathrm{OD}_{600}$ of the bacterial culture; $(\mathrm{X})$ Correlation curve of the experimental points located in the field of the validity of the Beer-Lambert law.

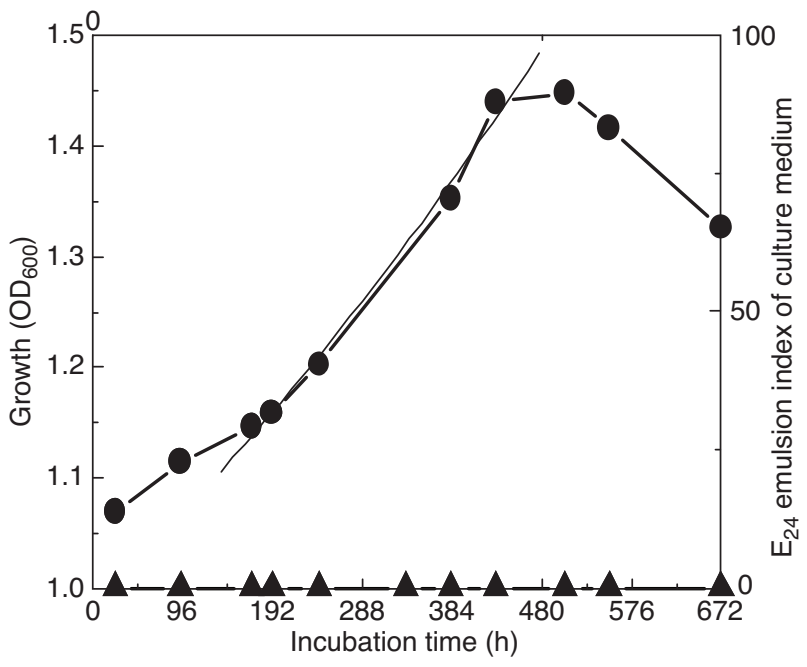

Figure 2

Growth of R. erythropolis 16 LM.USTHB with diesel oil used as the sole carbon source at the concentration $1 \%$ (vol/vol): $(-)$ Optical density $\left(\mathrm{OD}_{600}\right)$ of the culture medium; (A) $E_{24}$ emulsion index of the culture medium. 


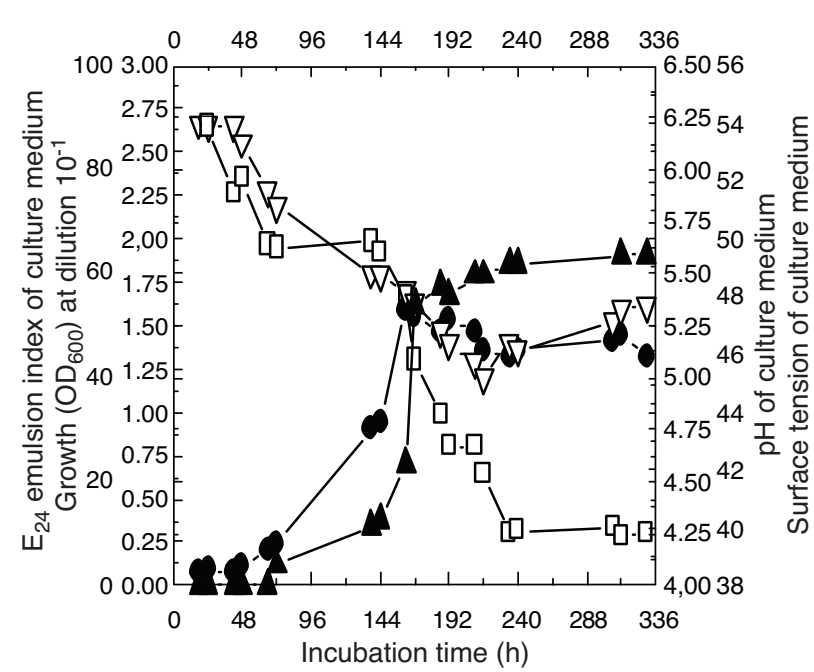

Figure 3

Growth of R. erythropolis 16 LM.USTHB with residual sunflower frying oil used as the sole carbon source at the concentration $3 \%$ ( $\mathrm{vol} / \mathrm{vol})$ :

(•) Optical density $\left(\mathrm{OD}_{600}\right)$ of the culture medium;

(ム) $\mathrm{E}_{24}$ emulsion index of the culture medium;

( $\square$ ) Surface tension of the culture medium;

$(\nabla) \mathrm{pH}$ of the culture medium.

The growth of the microorganism using the RSFO as the sole carbon source proceeded at the specific growth rate: $\mu=$ $0.55 \mathrm{~d}^{-1}(\mathrm{~d}=$ day $)$ during seven days of incubation. The dry mass increased from $0.4 \mathrm{mg} \mathrm{L}^{-1}$ to $1.2 \mathrm{mg} \mathrm{L}^{-1}$ during this exponential growth phase.

The residue of unutilized RSFO represents ca.1.5\% of the initial amount of RSFO.

The $\mathrm{pH}$ of the bacterial culture medium decreased from $\mathrm{pH}=6.22$ to $\mathrm{pH}=5.42$ during the exponential growth phase, as illustrated in Figure 3: the lowering of the $\mathrm{pH}$ of the culture medium during this phase was well correlated with the bacterial active growth phase (coefficient of correlation $R=-0.83$ ) and would result from the hydrolysis of the sunflower oil triglycerides and the release of fatty acids in the culture medium.

\subsection{Biosurfactant Production}

In this part of the work, we describe the use by Rhodococcus erythropolis 16 LM USTHB of RSFO as the sole carbon and energy source for producing surface-active agents. This production was detected by emulsifying activity and surface tension lowering when the microorganism was cultivated on MSM added with RSFO at the concentration 3\% (vol/vol).

\subsubsection{Emulsifying Activity}

Figure 3 shows the time course of the $\mathrm{E}_{24}$ emulsion index of the culture medium compared to the bacterial growth measured through the optical density $\left(\mathrm{OD}_{600}\right)$ of the culture medium diluted to $10^{-1}$. The $\mathrm{E}_{24}$ emulsion index increases from $4 \%$ after 3 days of incubation, to $54 \%$ at the end of the active growth phase: it means that the bacterial exponential growth phase is accompanied by the production of an emulsifying substance, which suggests that the microorganism assimilated the RSFO according to the mode of biosurfactant-mediated transfer; the process can have acted according to two ways: either making cellular surface more hydrophobic or the biosurfactant enhanced the aqueous solubilization and dispersion of the RSFO. During the stationary phase, the $\mathrm{E}_{24}$ emulsion index increases from 54\% to $63 \%$. We have observed that the emulsion was stable during several weeks.

It should be noted that the growth rate is 27 folds greater when the microorganism uses the RSFO as the sole carbon and energy source with production of an emulsifying agent, than when the microorganism uses the diesel oil as the sole carbon and energy source without emulsification of the culture medium.

\subsubsection{Surface Activity}

Figure 3 shows the evolution of the surface tension of the bacterial culture medium compared with the evolution of the $\mathrm{OD}_{600}$ of the bacterial growth. The surface tension of the culture medium decreases continuously from $54 \mathrm{mN} \mathrm{m}^{-1}$ to $46 \mathrm{mN} \mathrm{m}^{-1}$ during the exponential growth, and reaches the value $38.9 \mathrm{mN} \mathrm{m}^{-1}$ at the end of the stationary phase: that indicates the presence of a surface-active substance in the culture medium. The evolutions of the surface tension of the culture medium and the $\mathrm{E}_{24}$ emulsion index proceed in an antagonistic way with a coefficient of correlation $R=-0.86$. We can conclude that the microorganism produces biosurfactant, if we admit that microbial compounds, which exhibit particularly high surface activity and emulsifying activity, are classified as biosurfactants [22].

The test of localization of the biosurfactant produced by Rhodococcus erythropolis 16 LM. USTHB showed that the $\mathrm{E}_{24}$ emulsion index rate of the filtrate, for the sampling at 4 and 13 days of incubation, increases from $7.7 \%$ to $59.6 \%$, while in the same time, the surface tension of this filtrate decreases from $48.6 \mathrm{mN} \mathrm{m}^{-1}$ to $38.7 \mathrm{mN} \mathrm{m}^{-1}$, which proves that the produced biosurfactant is of extra-cellular nature.

The critical micelle concentration (CMC), which is a characteristic property of a surfactant, is the concentration at which micelles started to be formed: if more of the surfactant is present, there will be no further decrease in surface tension; it can be estimated from a semi-logarithmic plot of the surface tension of a solution versus the surfactant concentration. To obtain the CMC value of the crude biosurfactants, the crude extract from the bacterial culture 
was diluted in distilled water, and the surface tension was measured at various concentrations. As shown in Figure 4, the $\mathrm{CMC}$ of the crude product was reached at the point $X=\log \mathrm{C}=2.458$ and $Y=31.98$; thus the CMC of the crude product was $287 \mathrm{mg} \mathrm{L}^{-1}$ and corresponds to the surface tension $\gamma_{\mathrm{CMC}}=31.9 \mathrm{mN} \mathrm{m}^{-1}$.

After methylesterification of the fatty acid moiety, the results of GC-MS shown in Table 1 indicate that lipid fraction is essentially constituted by fatty acids like hexadecanoic acid which mass spectrum is presented in Figure 5. Peaks at $m / Z 270$ and 239 represent the molecular ion $\mathbf{M}^{+}$,

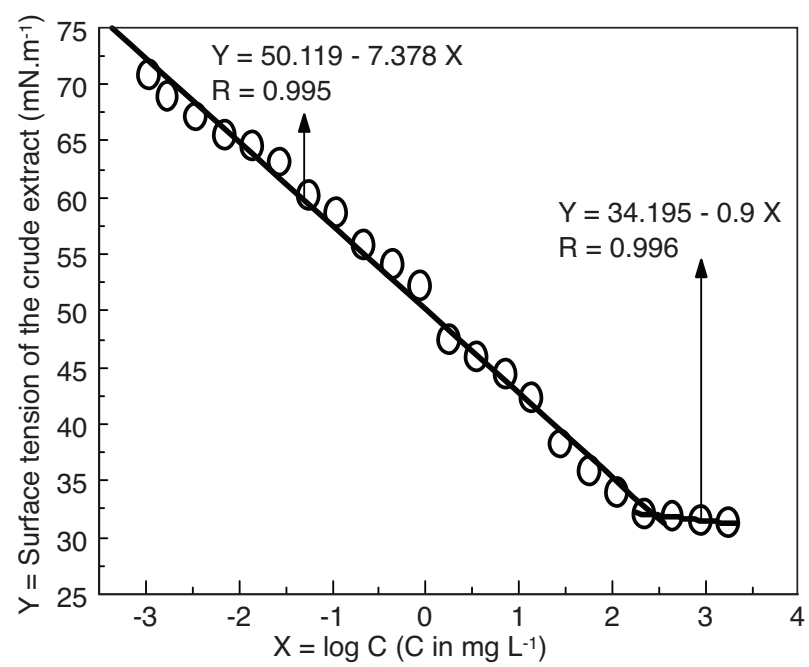

Figure 4

Surface tension vs. logarithm concentration for the crude extract. and molecular ion minus 31 mass units $\left(\mathrm{M}^{+}-31\right)$, acylium ion, respectively. The base peak at $m / Z 74$ and series of peaks at $m / Z$ 87, 143 and 227 indicated that it was a methylester of hexadecanoic acid. Using the Dubois method, the amount of sugar expressed in glucose equivalent was found $0.4 \mathrm{~g} \mathrm{~L}^{-1}$ : this means that Rhodococcus erythropolis 16 LM USTHB produces glycolipids, what is in agreement with studies that have been carried out with strains that belong to the Rhodococcus genus [14, 23, 24].

TABLE 1

Fatty acid composition of the lipid fraction of biosurfactant produced by R. erythropolis 16 LM.USTHB cultivated on RSFO; GC-MS data were derived from methyl esters

\begin{tabular}{c|c|c}
\hline Peak & Retention time $(\mathrm{min})$ & Methyl ester of \\
\hline 1 & 14.89 & Hexadecanoic acid \\
\hline 2 & 16.91 & 9-12 octadecadienoic acid (Z,Z) \\
\hline 3 & 17.03 & 9-octadecenoic acid (E) \\
\hline 4 & 17.07 & 9-octadecenoic acid (Z) \\
\hline
\end{tabular}

\section{CONCLUSION}

The results obtained suggest that Rhodococcus erythropolis 16 LM.USTHB can be used to reduce wastes generated by food industries, and to convert residual sunflower frying oil, a cheap renewable substrate, into higher value products; these products can be utilized with minimum purity specification, so that crude preparation could be applied for enhanced oil recovery: however, complementary studies should be undertaken in order to evaluate the conditions of

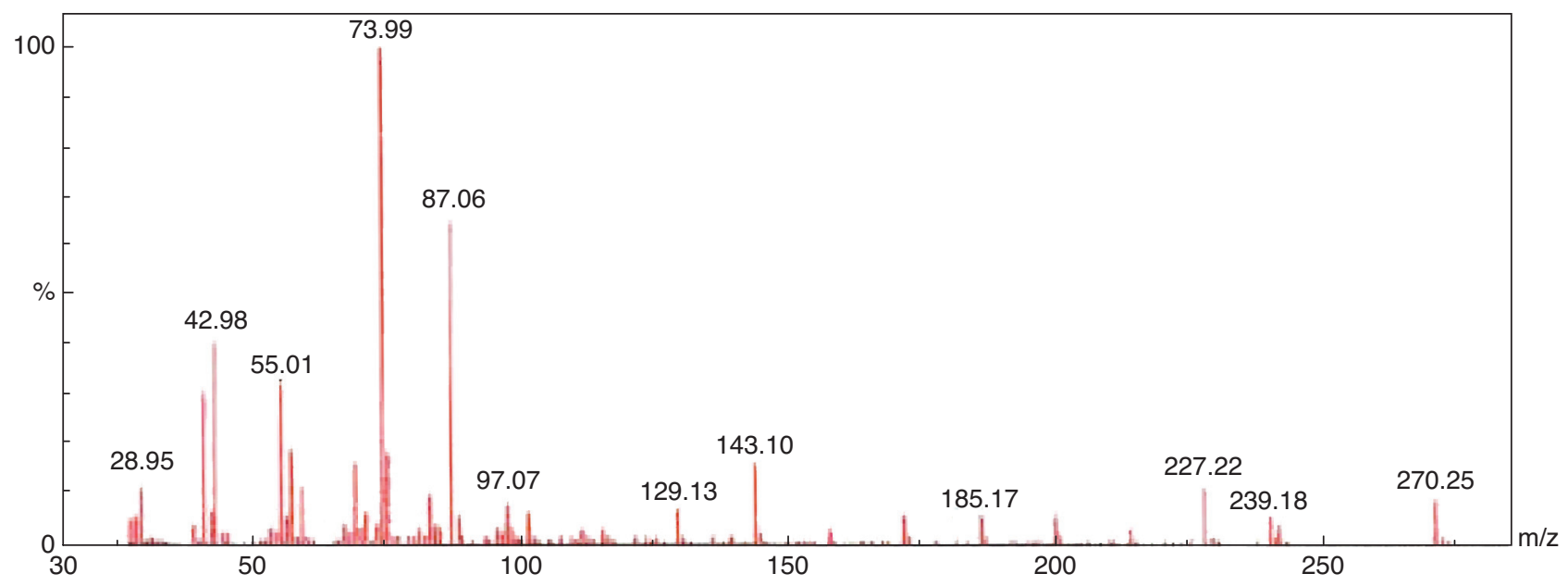

Figure 5

Mass spectrum of hexadecanoic acid methyl ester separated by Gas Chromatography from the fatty acid moiety of biosurfactant produced by R. erythropolis 16 LM.USTHB cultivated on RSFO used as the sole carbon source. 
feasibility of the process, which is an other and future work. They have also potentiel application in cleaning oil storage tanks: such a clean-up process can be more interesting that the conventional process.

We have established also that Rhodococcus erythropolis 16 LM USTHB is able to grow in the presence of diesel oil: thereby, the microorganism has potential for use in a variety of biotechnological applications, including bioremediation of hydrocarbons contaminated sites.

\section{ACKNOWLEDGEMENTS}

We thank the CRD/SONATRACH (Algerian Petroleum Company) for its assistance in materials and supplies.

We thank Pr. M.S. SEBIH and the Laboratory of Algiers Scientific Police Academy for measurement of GC-MS data.

This work is dedicated to the memory of Pr. A. Chikhi.

\section{REFERENCES}

1 Syldatk C., Wagner F. (1987) Production of biosurfactants, in Biosurfactants and biotechnology, Kosaric N., Cairns W.L., Gray N.C.C. (eds.), Marcel Dekker, Inc, New York.

2 Makkar R.S., Cameotra S.S. (2002) An update on the use of unconventional substrates for biosurfactant production and their new applications, Appl. Microbiol. Biot. 58, 428-434.

3 Van Hamme J.D., Singh A., Ward O.P. (2003) Recent advances in petroleum microbiology, Microbiol. Mol. Biol. R. 67, 4, 503-549.

4 Zhang Y., Miller R.M. (1992) Enhanced octadecane dispersion and biodegradation by a Pseudomonas rhamnolipid surfactant (biosurfactant), Appl. Environ. Microb. 58, 10, 3276-3282.

5 Zhang Y., Miller R.M. (1995) Structure on solubilization and biodegradation of n-alkanes, Appl. Environ. Microb. 61, 6, 22472251.

6 Al-Tahhan R.A., Sandrin T.R., Bodour A.A., Maier R.M. (2000) Rhamnolipid-induced removal of lipopolysaccharide from Pseudomonas aeruginosa: effect on cell surface properties and interaction with hydrophobic substrates, Appl. Environ. Microb. 66, $8,3262-3268$.

7 Crosman J.T., Pinchuk R.J., Cooper D.G. (2002) Enhanced biosurfactant production by Corynebacterium alkanolyticum ATCC 21511 using self-cycling fermentation, J. Am. Oil Chem. Soc. 79, $5,467-472$.

8 Desaï J.D., Banat I.M. (1997) Microbial production of surfactants and their commercial potential, Microbiol. Mol.Biol.R. 61, 1,47-64.

9 Van Dyke M.I., Lee H., Trevors J.T. (1991) Applications of microbial surfactants, Biotechnol. Adv. 9, 241-252.

10 Haba E., Espuny M.J., Busquets M., Manresa A. (2000) Screening and production of rhamnolipids by Pseudomons aeruginosa 47T2 NCIB 40044 from waste frying oils, J. Appl. Microbiol. 88, 3, 379-387.
11 Ferraz C., De Araujo A.A., Pastore G.M. (2002) The influence of vegetable oils on biosurfactant production by Serratia marcescens, Appl. Biochem. Biotech. 98, 100, 841-847.

12 Whyte L.G., Slagman S.J., Pietrantonio F., Bourbonnière L., Koval S.F., Lawrence J.R.R., Inniss W.E., Greer C.W. (1999) Physiological adaptations involved in alkane assimilation at a low temperature by Rhodococcus sp. strain Q15, Appl. Environ. Microb. 65, 7, 2961-2968.

13 Cooper D.G., Goldenberg B.G. (1987) Surface-active agents from two Bacillus Species, Appl. Environ. Microb. 53, 2, 224-229.

14 Rapp P., Lotte H.E.G.J. (2003) Degradation of alkanes and highly chlorinated benzenes, and production of biosurfactants, by a psychrophilic Rhodococcus sp. and genetic characterization of its chlorobenzene dioxygenase, Microbiology 149, 2879-2890.

15 Dubois M., Gilles K.A., Hamilton J.K., Rebers P.A., Smith F. (1956) Colorimetric method for determination of sugars and related substances, Anal. Chem. 28, 3, 350-356.

16 Button D.K. (1985) Kinetics of nutrient-limited transport and microbial growth, Microbiol. Rev. 49, 3, 270-297.

17 Bouchez M., Blanchet D., Vandecasteele J.P., Haeseler F. (1996) Polycyclic aromatic hydrocarbons in the environment. Part two: Microbial degradation, Oil Gas Sci. Technol. - Rev. IFP 51, 6, 797-828.

18 Bouchez-Naïtali M., Rakatozafy H., Marchal R., Leveau J.Y., Vandecasteele J.P. (1999) Diversity of bacterial strains degrading hexadecane in relation to the mode of substrate uptake, $J$. Appl. Microbiol. 86, 421-428.

19 Bouchez-Naïtali M., Blanchet D., Bardin V., Vandecasteele J.P. (2001) Evidence for interfacial uptake in hexadecane degradation by Rhodococcus equi: the importance of cell flocculation, Microbiology 147, 2537-2543.

20 Van Hamme J.D., Ward O.P. (2001) Physical and metabolic interactions of Pseudomonas sp. strain JA5-B45 and Rhodococcus sp. strain F9-D79 during growth on crude oil and effect of a chemical surfactant on them, Appl. Environ. Microb. 67, 10, 4874-4879.

21 Arino S., Marchal R., Vandecasteele J.P. (1998) Involvement of a rhamnolipid -producing strain of Pseudomonas aeruginosa in the degradation of polycyclic aromatic hydrocarbons by a bacterial community, J. Appl. Microbiol. 84, 5, 769-776.

22 Banat I.M., Makkar R.S., Cameotra S.S. (2000) Potential commercial applications of microbial surfactants, Appl. Microbiol. Biot. 53, 495-508.

23 Kuyukina M.S., Ivshina I.B., Philp J.C., Christofi N., Dunbar S.A., Ritchkova M.I. (2001) Recovery of Rhodococcus biosurfactants using methyl tertiary-butyl ether extraction, $J$. Microbiol. Meth. 46, 149-156.

24 Iwabuchi N., Sunairi M., Urai M., Itoh C., Anzai H., Nakajima M., Harayama S. (2002) Extracellular polysaccharides of Rhodococcus rhodochrous S-2 stimulate the degradation of aromatic components in crude oil indigenous marine bacteria, Appl. Environ. Microb. 68, 5, 2337-2343.

Final manuscript received in June 2008 Published online in September 2008 or distributed for profit or commercial advantage and that copies bear this notice and the full citation on the first page. Copyrights for components of this work owned by others than IFP must be honored. Abstracting with credit is permitted. To copy otherwise, to republish, to post on servers, or to redistribute to lists, requires prior specific permission and/or a fee: Request permission from Documentation, Institut français du pétrole, fax +33147527078 , or revueogst@ifp.fr. 